\section{Asbestos: killer dust, says book}

A new book on asbestos claims half a million will die in the UK of asbestos-induced cancer. Alastair Hay reports

Five hundred thousand people will die from asbestos-related diseases in the UK in the next forty years according to a book published recently by the British Society for Social Responsibility in Science. In 'Asbestos Killer Dust' the author, Dr Alan Dalton, says that a 1978 US Government Report on asbestos-related cancer deaths makes possible the prediction that a "real epidemic of asbestos related diseases" is about to occur in Britain.

The US report, published by the National Institute of Environmental Health Sciences (NIEHS) estimated that over 2 million American workers will die of cancer as a result of occupational exposure to asbestos. Thus, says Dalton, in Britain - with a population roughly a quarter of that in the US - it can be assumed that asbestos will kill some half million people.

Is the future that grim? It could be, says Dalton, if the recent reports from the US are correct and if Britain does nothing about the current standards regulating asbestos fibre concentrations in the workplace. The standards - based on the number of fibres per millilitre of inhaled air-differ for the various types of asbestos used. Current UK recommendations are 0.2 fibres $\mathrm{ml}^{-1}$ for blue (crocidolite) asbestos and 2.0 fibres $\mathrm{ml}^{-1}$ for white (chrysotile), brown (amosite) and any other fibre.

According to Dalton the present British standards allow much too high a concentration, and far from being safe present a positive danger to health. Citing a 1976 US National Institute for Occupational Safety and Health (NIOSH) report that there is $n o$ safe level for asbestos, the author questions the justification for the British standard.

Dalton points out that, in its report, NIOSH recommended a new US standard of 0.1 fibre $\mathrm{ml}^{-1}$-but that even this was chosen because of practical problems in taking accurate measurements of asbestos fibre concentrations. Why then, the author asks, is the British standard for white asbestos 20 times that recommended for the US? And why he questions, does Britain persist with its two-tier standard for blue and white asbestos when NIOSH recommends one standard for both? Mesothelioma, the asbestos-related cancer, Daton points out, is now quite clearly attributable to exposure to both types of asbestos and not just to the blue form as was originally believed.

The British standards are currently being reviewed by the Advisory Committee on Asbestos of the Health and Safety Executive (HSE), and a report stating the Executive's view on the adequacy of the standard is expected in the next 2-3 months. It has been reported that the committee will recommend that the standard for white asbestos should be halved to 1 fibre $\mathrm{ml}^{-1}$, matching Sweden's should be reduced to 0.5 fibre $\mathrm{ml}^{-1}$; and that blue asbestos should be banned, with the standard for its removal remaining at the present 0.2 fibres $\mathrm{ml}^{-1}$.

It is quite clear, however, that the original study at the Turner and Newall factory in Rochdale in 1966 which laid the basis for the British standard was flawed. The number of asbestos-related health problems was considerably underestimated. Only workers who had completed 10 years service and were still in the company's employ were included in the study; those who had left the factory were not followed up. In addition the clinical test used to assess the effect of accumulated asbestos exposure has been criticised as being too stringent.

The test measures the prevalence of crepitations (abnormal sounds in the lung during exhalation and inhalation) and it has been suggested that this test might only identify more serious asbestos injury and miss cases with minor damage. Furthermore, there are indications that the dose/response data from the Turner study may in fact be wrong, as the dust level was actually higher than originally reported.

Although there is no official comment from UK Regulatory Authorities on the 1978 NIEHS report for asbestos related about it in private. For example, it is known that the HSE feels that figures for deaths in the US cannot be applied to the UK. Scientists at the HSE are known to have doubts about the validity of the assumption in the NIEHS report that the "relative risk" of developing cancer is constant throughout life. Furthermore assuming the most conservative estimate of risk in the NIEHS report it can be calculated that at least 5000 deaths from mesothelioma should be occurring annually. In 1976, however, the US figure was 1000 deaths.

Even though the HSE feel that Dalton has considerably over-estimated the dangers, the Executive does admit that mesothelioma deaths present a real problem. Figures collected by HSE's Employment Medical Advisory Service show that deaths from mesothelioma have risen inexorably since 1968. EMAS figures for $1968,1972,1974,1977$ are 154, 208, 230 and 323 deaths respectively. An HSE spokesman pointed out that the mesotheliomas may not have been due to asbestos; but he did confess that it was almost certain that they were.

'Asbestos Killer Dust' by Alan J.P. Dalton. Published by the British Society for Social Responsibility in Science. 9 Poland Street, London WIV $3 D$ G. Price $£ 2.25$ limits; that the limit for brown asbestos cancer deaths, criticisms have been made
Desai's difficulties with AT

\section{Alternative technology is no simple panacea for India writes Anil Agarwal}

WITH the emergence of the Janata government in 1977, considerable hopes were raised both within the country and outside, that India would become a major Third World country actively using and supporting appropriate technology (AT). The need for AT was mentioned in the election manifesto of the Janata Party and, in his very first broadcast to the nation, Prime Minister Morarji Desai, had emphasised that "the big city, the big machine and big science have their place. But they cannot claim a prescriptive right to preference and dominance. We have to make the village the centre of our economic progress."

The industrial policy announced by the Janata government in December 1977 also recognised the importance of reducing unemployment and rural-urban disparities in India's future industrialisation programmes. Although India is today the tenth largest industrial producer in the world, the total number of its unemployed is almost equal to the total number of those employed by all its organised mills, factories and services. Mr George Fernandes, the Janata Industries Minister, therefore, declared that AT "will henceforth be an integral part of policy and government will ensure that this important area gets adequate attention." The Janata government, he stated, "will not favour large scale industry merely for demonstration of sophisticated skills or as monuments of foreign technology. The main thrust of the new industrial policy will be on effective promotion of cottage and small industries widely dispersed in rural areas and small towns."

AT, thus, appeared to be in early 1978 not only a sensible option for India, but also one of enjoying great support. However, over the months the initial resolve of the Janata government in favour of small-scale labour-intensive ruraloriented AT was weakened. This was, to a great extent, because of the myriad interparty factional tensions, which virtually sapped the very will of the government to govern, but partly also because of the strong opposition from scientific and industrial establishments.

The Janata government's advocacy of AT was unfortunately accompanied by a barrage of criticism of the country's past scientific and technological activity. The critics argued that the country had not adequately benefited from its large investments in R\&D institutions and that 